\title{
Therapy-induced antitumor vaccination in neuroblastomas by the combined targeting of IL-2 and TNF $\alpha$
}

\author{
Enrica Balza ${ }^{1}$, Barbara Carnemolla ${ }^{2}$, Lorenzo Mortara ${ }^{3}$, Patrizia Castellani ${ }^{1}$, Debora Soncini ${ }^{1}$, \\ Roberto S. Accolla ${ }^{3}$ and Laura Borsi ${ }^{1}$ \\ ${ }^{1}$ Cell Biology Laboratory, Department of Translational Oncology, Istituto Nazionale per la Ricerca sul Cancro, Genova, Italy \\ ${ }^{2}$ Laboratory of Immunology, Department of Translational Oncology, Istituto Nazionale per la Ricerca sul Cancro, Genova, Italy \\ ${ }^{3}$ Department of Clinical and Biological Sciences, School of Medicine, University of Insubria, Varese, Italy
}

L19-IL2 and L19TNF $\alpha$ are fusion proteins composed of L19(scFv), specific for the angiogenesis-associated ED-B containing fibronectin isoform and IL-2 or TNF $\alpha$. Because of the tumor targeting properties of L19, IL-2 and TNF $\alpha$ concentrate at therapeutic doses at the tumor vascular level. To evaluate the therapeutic effects of L19-IL2 and L19mTNF $\alpha$ in neuroblastoma (NB)-bearing mice, A/J mice bearing Neuro2A or NIE115 NB were systemically treated with L19-IL2 and L19mTNF $\alpha$, alone or in combination protocols. Seventy percent of Neuro2A- and 30\% of NIE115-bearing mice were cured by the combined treatment with L19-IL2 and L19mTNFa, and further rejected a homologous tumor challenge, indicating specific antitumor immune memory. The immunological bases of tumor cure and rejection were studied. A highly efficient priming of $\mathrm{CD} 4^{+} \mathrm{T}$ helper cells and $\mathrm{CD} 8^{+}$CTL effectors was generated, paralleled by massive infiltration in the tumor tissue of $\mathrm{CD} 4^{+}$and $\mathrm{CD} 8^{+} \mathrm{T}_{\text {cells }}$ at day 16 after tumor cell implantation, when, after therapy, tumor volume was drastically reduced and tumor necrosis reached about $80 \%$. The curative treatment resulted in a long-lasting antitumor immune memory, accompanied by a mixed Th1/Th2 type of response. Concluding, L19-IL2 and L19mTNF $\alpha$ efficiently cooperate in determining a high percentage of NB cure that, in our experimental models, is strongly associated to the generation of adaptive immunity involving $\mathrm{CD} 4^{+}$and $\mathrm{CD} 8^{+} \mathrm{T}_{\text {cells. }}$

Neuroblastoma (NB) is one of the most common solid tumors of childhood, accounting for $8-10 \%$ of all pediatric cancers and $15 \%$ of cancer-related deaths. Therapy of NB has mainly consisted of chemotherapy followed by surgical resection of the tumor or radiotherapy. ${ }^{1}$ Strategies to address minimal residual disease have included high-dose chemotherapy

Key words: neuroblastoma, oncofetal fibronectin, angiogenesis, tumor targeting, immunotherapy

Grant sponsor: Fondi di Ateneo per la Ricerca (FAR) 2008: "Study of antigenic stimulation in the tumor microenvironment" (L.M. and R.S.A.); I.S.S. National Research Project on A.I.D.S. n_45G.1

(R.S.A.); Cariplo Foundation ref. Project 2008-2230 "Cellular and molecular basis of human retroviral-dependent pathology: new immunological and biochemical approaches to counteract retrovirus infection and replication, relevant for the design of novel preventive and therapeutic strategies" (R.S.A)., Istituto Superiore di Sanità, Rome, Italy; Grant number: ISS2006-Rare diseases; Grant sponsor: Italian Ministry of Health, Rome, Italy; Grant numbers: RF-IST-2006-384590, RF-IGG-2004-625731; Grant sponsor: Alleanza Contro il Cancro; Grant number: ACC2007 DOI: $10.1002 /$ ijc. 25018

History: Received 7 Aug 2009; Accepted 22 Oct 2009; Online 29 Oct 2009

Correspondence to: Laura Borsi, Cell Biology Laboratory, Department of Translational Oncology, Istituto Nazionale per la Ricerca sul Cancro, Largo Rosanna Benzi, 10, 16132 Genova, Italy, Tel: +[ 39010 5737390], Fax: +[39010 5737560],

E-mail: laura.borsi@istge.it with autologous hematopoietic stem cell rescue or differentiation of the remaining malignant cells with retinoids. ${ }^{2}$ However, because success rates with these approaches have been limited, alternative strategies, including immunotherapy, have increasingly become the subject of investigation. ${ }^{3}$ Inflammatory cytokines such as interleukin-2 (IL-2) and tumor necrosis factor alpha (TNF $\alpha$ ) have been explored for the treatment of cancers $^{4-7}$ : the former has shown antitumor activity and is currently used for the treatment of NB mainly because of its ability to activate and enhance the cytolytic activity of NK and $\mathrm{T}$ cells ${ }^{8,9}$; $\mathrm{TNF} \alpha^{10,11}$ exerts antitumor effects via a preferential toxicity for the endothelial cells of the tumor-associated vasculature, resulting in extensive tumor necrosis, and through an increase of the antitumor immune response. ${ }^{12-16}$ The systemic administration of cytokines in pharmacological doses often produces suboptimal levels in the tumor microenvironment ${ }^{17}$ and, as in the case of TNF $\alpha$, can induce unacceptable toxic side effects that confine their use to strictly controlled loco-regional treatments. ${ }^{18}$

We previously demonstrated that $\mathrm{B}-\mathrm{FN}$, the fibronectin isoform containing the extra-domain $\mathrm{B}$ (ED-B), is a marker of angiogenesis, ${ }^{19,20}$ and that endothelial cells invading tumor tissues migrate along extra cellular matrix (ECM) fibers containing B-FN. ${ }^{21}$ Subsequent results demonstrating the possibility to selectively target tumor vasculature using a human recombinant antibody specific for B-FN, L19(scFv), in both experimental animal models and cancer patients, ${ }^{21,22}$ paved the way for the antibody's use in vivo for both diagnostic and therapeutic purposes. Indeed, the selective targeted 
delivery to the ED-B domain of fibronectin using L19(scFv) dramatically enhances the anticancer properties of cytokines $^{23-25}$ and circumvents most of the adverse side effects.

We generated the fusion proteins L19-IL2 ${ }^{23}$ and L19mTNF $\alpha,{ }^{24}$ conjugating L19(scFv) with human IL-2 and mouse TNF $\alpha(\mathrm{mTNF} \alpha)$, respectively. When injected intravenously (i.v.) into tumor-bearing mice these fusion proteins selectively accumulate around the tumor vasculature ${ }^{23,24}$ where they can exert their anticancer activities. For the tumor-targeting and preclinical therapeutic performances, ${ }^{22-24}$ these fusion proteins are presently undergoing testing in phase I/II clinical trials. ${ }^{26,27}$

Both fusion proteins showed anticancer therapeutic effects that are synergistically enhanced by combined treatment in preclinical studies. ${ }^{24}$

With the aim to improve the antitumor efficacy of IL-2, already used for $\mathrm{NB}$, we treated NB-bearing mice with a combination of L19-IL2 and L19mTNFa. Herein, we report the results achieved.

\section{Material and Methods Animal tumor models}

Two different NB cell lines, Neuro2A (N2A, kindly provided by Dr. S. Ferrini, Laboratory of Immunological Therapy, Istituto Nazionale per la Ricerca sul Cancro, Genova, Italy) and NIE-115 (European Collection of Animal Cell Cultures, Sigma-Aldrich, Milan, Italy), all of A/J origin, were subcutaneously (s.c.) implanted in the left flank of immunocompetent syngeneic $\mathrm{A} / \mathrm{J}$ mice at the dose of $0.25 \times 10^{6}$ cells/ mouse. All mice were 8 to 10 weeks old and were purchased from Harlan, UK (Oxon, United Kingdom). The tumor volume was determined using the following formula: $(d)^{2} \times D$ $\times 0.52$; where $d$ and $D$ are the short and long dimensions $(\mathrm{cm})$ of the tumor, respectively, measured with calipers. ${ }^{28}$ The mice were sacrificed when the tumor reached a volume of $1.5 \mathrm{~cm}^{3}$. Housing, treatment and sacrifice of animals were compliant with national legislative provisions (Italian law no. 116; January 27, 1992) for the protection of animals used for scientific purposes.

\section{Tumor therapy}

Groups of NB-bearing mice (when the tumors reached a volume of about $0.1 \mathrm{~cm}^{3}$ ) were injected, following the schedule reported in Figure 2, in their tail vein with the fusion proteins $\mathrm{L} 19 \mathrm{mTNF} \alpha(0.7 \mathrm{pmol} / \mathrm{g}$ in combination therapies and $1 \mathrm{pmol} / \mathrm{g}$ as a single drug) and/or L19-IL2 (20 $\mu \mathrm{g}=240,000$ IL-2 IU/mouse), or with equivalent amounts of recombinant mTNF $\alpha$ (Peprotech, London UK), and IL-2 (Proleukin, $18 \times$ $10^{6} \mathrm{IU} / \mathrm{ml}$; Chiron, Emeryville, CA) in $100 \mu \mathrm{l}$ of PBS (20 $\mathrm{mM}$ sodium phosphate buffer $\mathrm{pH} 7.6,150 \mathrm{mM} \mathrm{NaCl}$ ). The expression, purification and characterization of the fusion proteins are reported elsewhere. ${ }^{23,24}$ Control groups received $100 \mu \mathrm{l}$ of PBS only. The weight of the animals and the tumor volume were recorded at $24-\mathrm{hr}$ intervals before and after treatments. Toxicity was evaluated on the basis of weight loss, as previously reported. ${ }^{24}$

\section{In vivo cell subset depletion and in vitro cell subset selection}

In vivo cell subset depletions were performed as previously described $^{29}$ following the protocol reported in Figure $4 a$ by intraperitoneal (i.p.) injections of anti-CD4 (GK1.5; ATTC, Rockville, MD), anti-CD8 (2.43; ATTC) rat mAbs and antiasialo-GM1 (anti-NK rabbit serum; Wako Chemicals GmbH, Dusseldorf, Germany). Control animals received normal rabbit serum or an irrelevant rat $\mathrm{mAb}$, as described. ${ }^{29}$ In vivo depletion efficiency for each cellular subset was always $>90 \%$, as assessed by immunofluorescence and cytofluorimetric analysis (Becton Dickinson, Milan, Italy) on splenocytes of 2 mice taken from each group by direct staining with FITC conjugated anti-CD4 YTS 191.1.2 mAb (Immunotools, $\mathrm{GmbH}$, Germany), PE-conjugated anti-CD8 YTS 169.4 mAb (Immunotools), or FITC-conjugated DX-5 mab (Caltag-Medsystems Limited, Buckingham, UK) for NK cells. For in vitro selection of $\mathrm{CD}^{+}$and $\mathrm{CD} 8^{+}$spleen cells, an immunomagnetic procedure was used: briefly, negative selection was performed with a pool of mAbs specific for all cells except $\mathrm{CD}^{+}{ }^{+}$or $\mathrm{CD}^{+}$cells $\left(\mathrm{CD} 4^{+}\right.$and $\mathrm{CD} 8 \mathrm{a}^{+} \mathrm{T}$ cell isolation kits, respectively; Miltenyi Biotec $\mathrm{GmbH}$, Bergisch Gladbach, Germany). Purity was $>95 \%$, as assessed by immunofluorescence and FACS analysis.

\section{Immunohistochemical analyses}

Cryostat sections (6 $\mu \mathrm{m}$ thick) were air-dried and fixed in cold acetone for $10 \mathrm{~min}$. Immunostaining was performed using a previously described procedure ${ }^{19}$ and the following primary antibodies: L19 human IgG1 to detect B-FN, ${ }^{28}$ antiCD4 (GK1.5), anti-CD8 (2.43), antigranulocyte Ly-6G (Gr-1; clone RB6-8C5; ImmunoKontact, Lugano, Switzerland), antimacrophage (clone MOMA-1; ImmunoKontact, Lugano, Switzerland), anti-B (clone RA3-3A1/6.1; ATCC) and antiNK (anti-asialo-GM1, Wako Biochemicals, Osaka, Japan). Quantitative studies of stained sections were performed independently by 3 researchers in a blind fashion. Cell counting was carried out in 8-12 randomly chosen fields under a Leica Wetzlar light microscope (Solms, Germany) at $400 \times$ magnification, $0.180 \mathrm{~mm}^{2} /$ field. The results are expressed as cell number per high magnification microscopic field (cell no./ HMMF, mean \pm SE). Mann Whitney $U$-test was used to evaluate statistically significant differences between the groups. The percentage of tumor necrosis was evaluated independently by 3 researchers on 5 not serial cryostat sections stained with hematoxylin and eosin at $200 \times$ magnification.

\section{Cell adoptive immunity transfer experiments (Winn assay)}

N2A or NIE-115 tumor-cured mice were given a s.c. booster dose in the contralateral flank with cells derived from the same tumors $\left(0.25 \times 10^{6}\right)$ and, after 12 days, the total splenocytes were obtained, following the procedure described by 

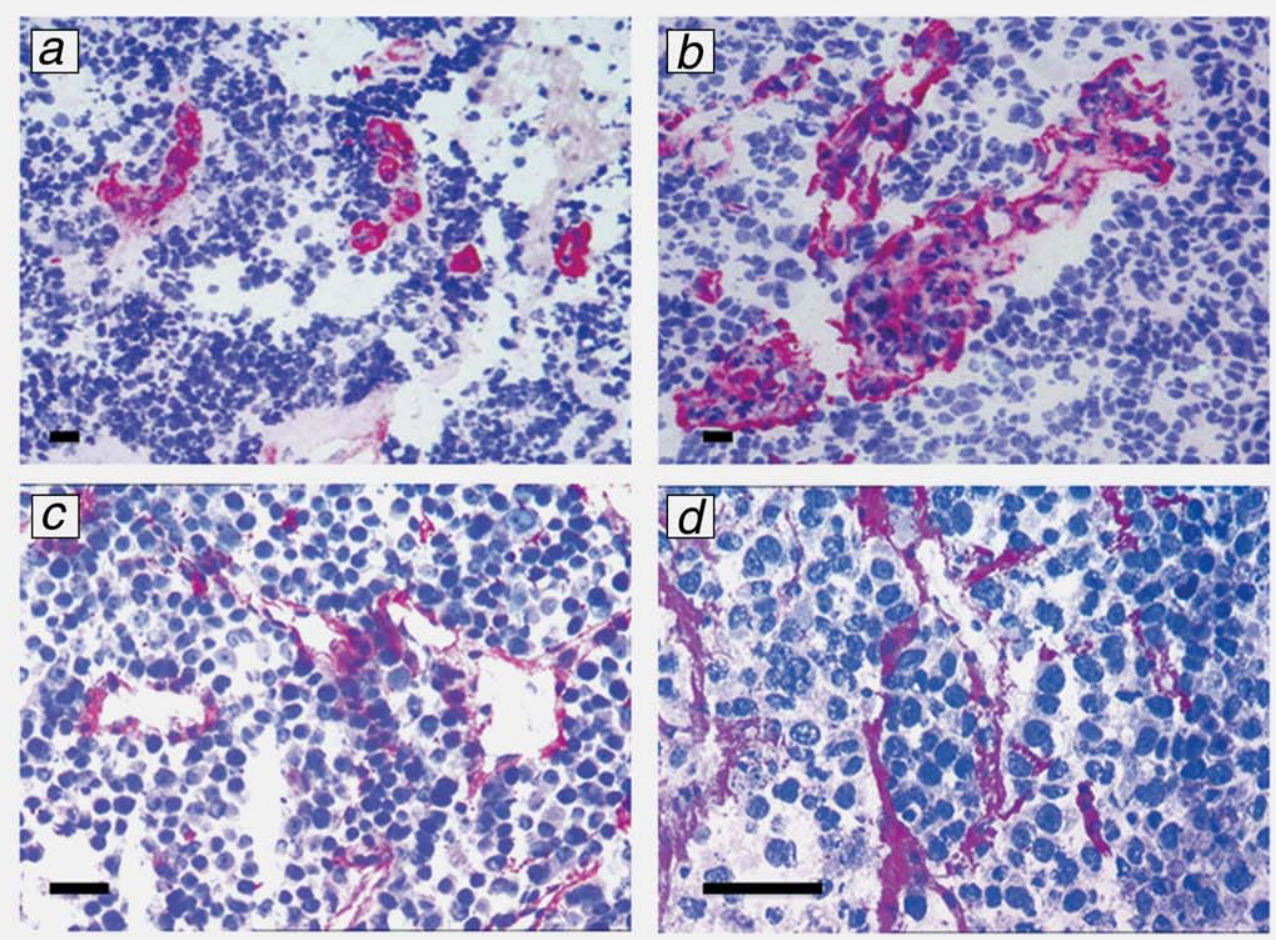

Figure 1. Immunohistochemical analysis of the expression of B-FN on cryostat sections of two patient-derived NB specimens (a-b), mouse N2A (c) and NIE-115 (d) NBs. The pattern of B-FN staining, obtained using L19(scFv), is quite similar in all the tumors tested and restricted to the vascular level. Scale bars, $10 \mu \mathrm{m}$.

Balza et al. ${ }^{30}$ To establish the amount of effector splenocytes able to protect naïve mice against N2A or NIE-115 tumor, different effector-tumor cell ratios (E:T), from 10:1 to 1:1, were calculated. In the adoptive immunity transfer experiments, an E:T ratio of 5:1 was used with N2A and NIE-115 tumors.

\section{ELISPOT assay}

Frequencies of IFN- $\gamma$ - or IL-4-producing spleen cells were determined using an enzyme-linked immunospot (ELISPOT) assay performed with ex vivo total splenocytes cocultured with irradiated N2A or NIE115 tumor cells as antigen, as described by Mortara et al. ${ }^{31} \mathrm{~A}>2$-fold increase in the number of spots over the control (splenocytes cultured in the absence of tumor cells) was considered a positive response. In certain experiments, mAbs specific for either MHC class I (34.1.2S clone, $50 \mu \mathrm{g} / \mathrm{ml}$ ) or class II (K24.199 and K22.42.2 clones, $50 \mu \mathrm{g} / \mathrm{ml}$ ) antigens were added during the coculture with irradiated tumor cells. Moreover, immune splenocytes from N2A tumor-cured mice were stimulated in vitro for 5 days with $10 \mu \mathrm{g} / \mathrm{ml}$ of the following peptides (Tib MolBiol, Berlin, Germany; kindly provided by Dr S. Ferrini, Istituto per La Ricerca sul Cancro, Genova, Italy) ${ }^{32}$ : SPSYVYHQF (gp70env-derived AH1 peptide), and GWEPDDNPI (SURV2) and analyzed for IFN- $\gamma$ production, in the absence or presence of anti-MHC class I ( $34.1 .2 \mathrm{~S}$ clone, $50 \mu \mathrm{g} / \mathrm{ml}$ ) or
anti-MHC class II (K24.199 and K22.42.2 clones, $50 \mu \mathrm{g} / \mathrm{ml}$ ) antibody. Data are expressed as number of spot-forming cells per million spleen cells.

\section{Cell-mediated cytotoxicity assay}

The cell-mediated cytotoxicity assay was performed using splenocytes from naïve, N2A tumor-cured or N2A tumorbearing mice. Splenocytes were cocultured with irradiated $\mathrm{N} 2 \mathrm{~A}$ cells for 5 days in the presence of $25 \mathrm{IU} / \mathrm{ml} \mathrm{IL}-2$ and then tested in a standard $4-\mathrm{hr}{ }^{51} \mathrm{Chromium}$-release assay on N2A or NIE-115 target cells, as reported by Balza et al., ${ }^{30}$ in the absence or presence of anti-MHC class I (34.1.2S clone, $50 \mu \mathrm{g} / \mathrm{ml}$ ) or anti-MHC class II (K24.199 and K22.42.2 clones, $50 \mu \mathrm{g} / \mathrm{ml}$ ) antibody.

\section{Results \\ Eradication of established tumors}

Two distinct NB cell lines, Neuro2A (N2A) and NIE-115, were injected s.c into syngeneic $\mathrm{A} / \mathrm{J}$ mice at the dose of 0.25 $\times 10^{6}$ cells/mouse. This dose induces a tumor of about 0.1 $\mathrm{cm}^{3}$ in 8 days. These are fast growing tumors that normally kill animals in about 3 weeks.

Immunohistochemistry of N2A (Fig. 1c) and NIE115 (Fig. 1d) revealed a strong expression of B-FN at the tumor vascular level, similar to a staining pattern found in patientderived NB specimens (Figs. $1 a$ and $1 b$ ). The expression of 


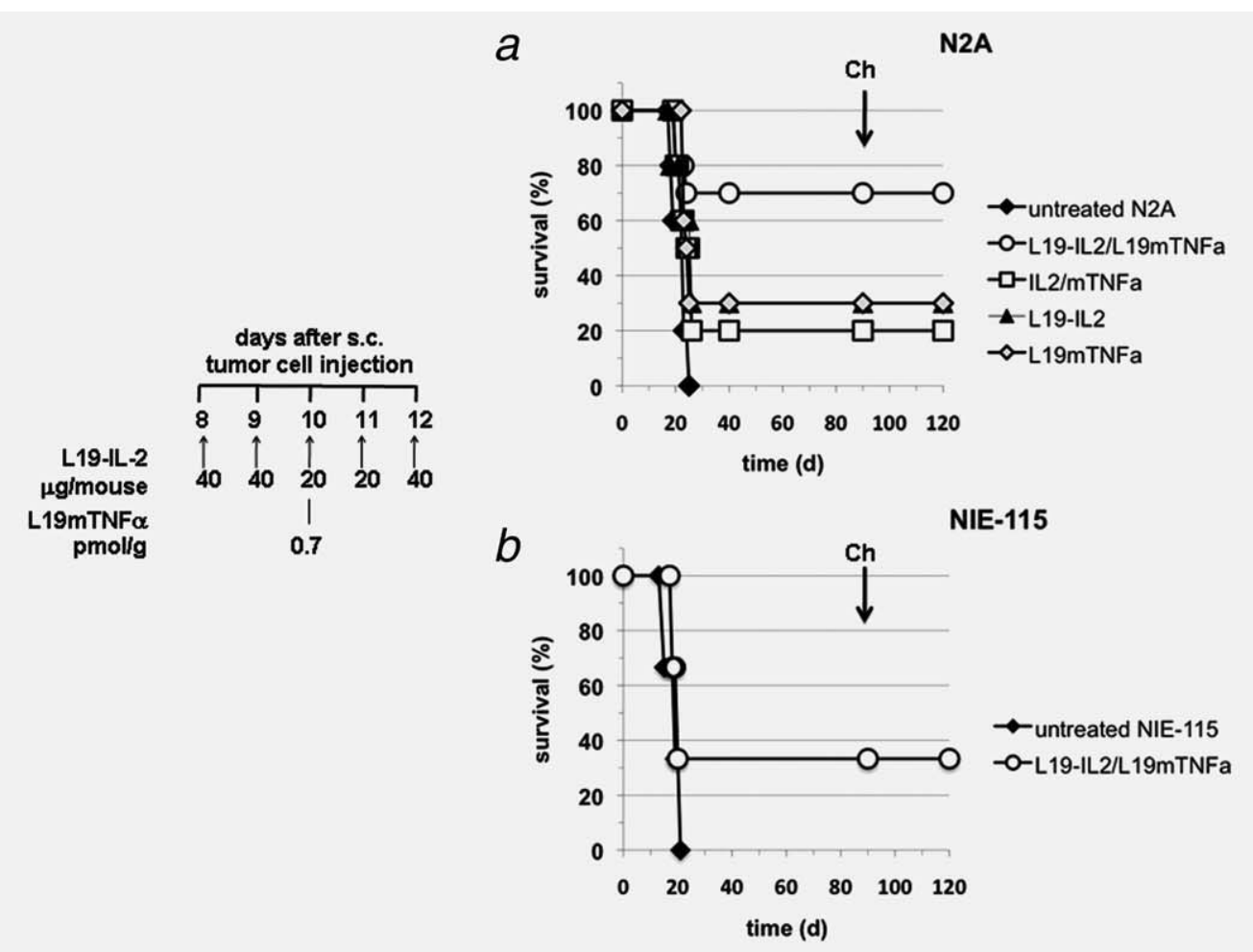

Figure 2. Therapeutic efficacy of L19-IL2 and L19mTNF $\alpha$ on N2A (a) and NIE-115 (b) mouse NB models. The therapeutic protocol reported was applied to both models. The different treatments are indicated. Ten mice per group were used and the results are expressed as survival (\%) versus time (d). The arrows indicate the tumor challenge.

B-FN, a tumor-associated marker and a marker of angiogenesis, ${ }^{19,20}$ is considered an important prerequisite for the $\mathrm{L} 19$ (scFv)-driven tumor targeting of effector molecules, as in the case of the fusion proteins used in this study for therapeutic purposes.

We tested the effects of L19-IL2 and L19mTNF $\alpha$, given alone or in the combination protocol reported in Figure 2, in groups of 10 mice bearing $\mathrm{N} 2 \mathrm{~A}$ tumors of $\sim 0.1 \mathrm{~cm}^{3}$. The results, shown in Figure $2 a$, indicated that the best therapeutic efficacy in N2A-bearing mice was obtained using the combination of L19mTNFa and L19-IL2 (70\% of long-lasting tumor eradication up-to 6 months after therapy). On the other hand, combined treatment with equivalent amounts of unconjugated cytokines resulted in tumor eradication in only $20 \%$ of animals. Moreover, treatment with either L19-IL2 or $\mathrm{L} 19 \mathrm{mTNF} \alpha$ alone resulted in only $30 \%$ of tumor-cured mice. The combined treatment with L19mTNF $\alpha$ and L19-IL2 also led to complete and long-lasting tumor eradication in $30 \%$ of NIE-115-bearing mice (Fig. 2b). The combined treatment was well tolerated by tumor-bearing mice, as they never had weight loss exceeding 5\% during and after the therapy. The mice remained tumor-free for at least 6 months after therapy. Importantly, as previously demonstrated in other tumor models, ${ }^{30,31}$ cured mice fully rejected the challenge with a tumorigenic dose of cells 3 months after therapy, demonstrating that treatment with L19mTNFa and L19-IL2 induced a protective immune response in the treated animals.

\section{Tumor tissue correlates of immunity}

To gain better insight into the immune-mediated mechanisms associated with treatment, we investigated the phenotype of tumor-infiltrating leukocytes on N2A cryostat sections at different times (Fig. 3) in mice untreated and treated following the protocol reported in Figure 2. Tumors were removed at day 8, 11 and 16 after tumor cell implantation. Among the tumor-infiltrating cells analyzed, NK cells showed no differences in the treated and untreated mice at any time points analyzed (Fig. 3, NK). By contrast, $\mathrm{CD}^{+}$and $\mathrm{CD}^{+} \mathrm{T}$ cells, B cells, macrophages (MФ), granulocytes (Gr) and dendritic cells (DC) were all statistically significantly increased in treated mice compared to untreated controls, especially at day 16, when tumor volume was drastically reduced after therapy and tumor necrosis reached nearly $80 \%$ (see Fig. 3).

\section{In vivo depletion of $\mathrm{CDB}^{+} \mathrm{T}$ cells abolishes the therapeutic efficacy of L19-IL2 and L19mTNFa}

To study the relative contribution of distinct lymphocyte subpopulations in the early processes leading to tumor cure, groups of $10 \mathrm{~A} / \mathrm{J}$ mice were deprived of $\mathrm{CD} 4^{+} \mathrm{T}$ cells, $\mathrm{CD} 8^{+}$ $\mathrm{T}$ cells or NK cells by injecting specific antibodies or antisera intraperitoneally, according to the scheme reported in Figure $4 a$, where day 0 corresponds to $\mathrm{N} 2 \mathrm{~A}$ tumor cell injection. At day 8 , the therapy was initiated following the protocol also reported in Figure 4a. Removal of NK cells did not affect the 

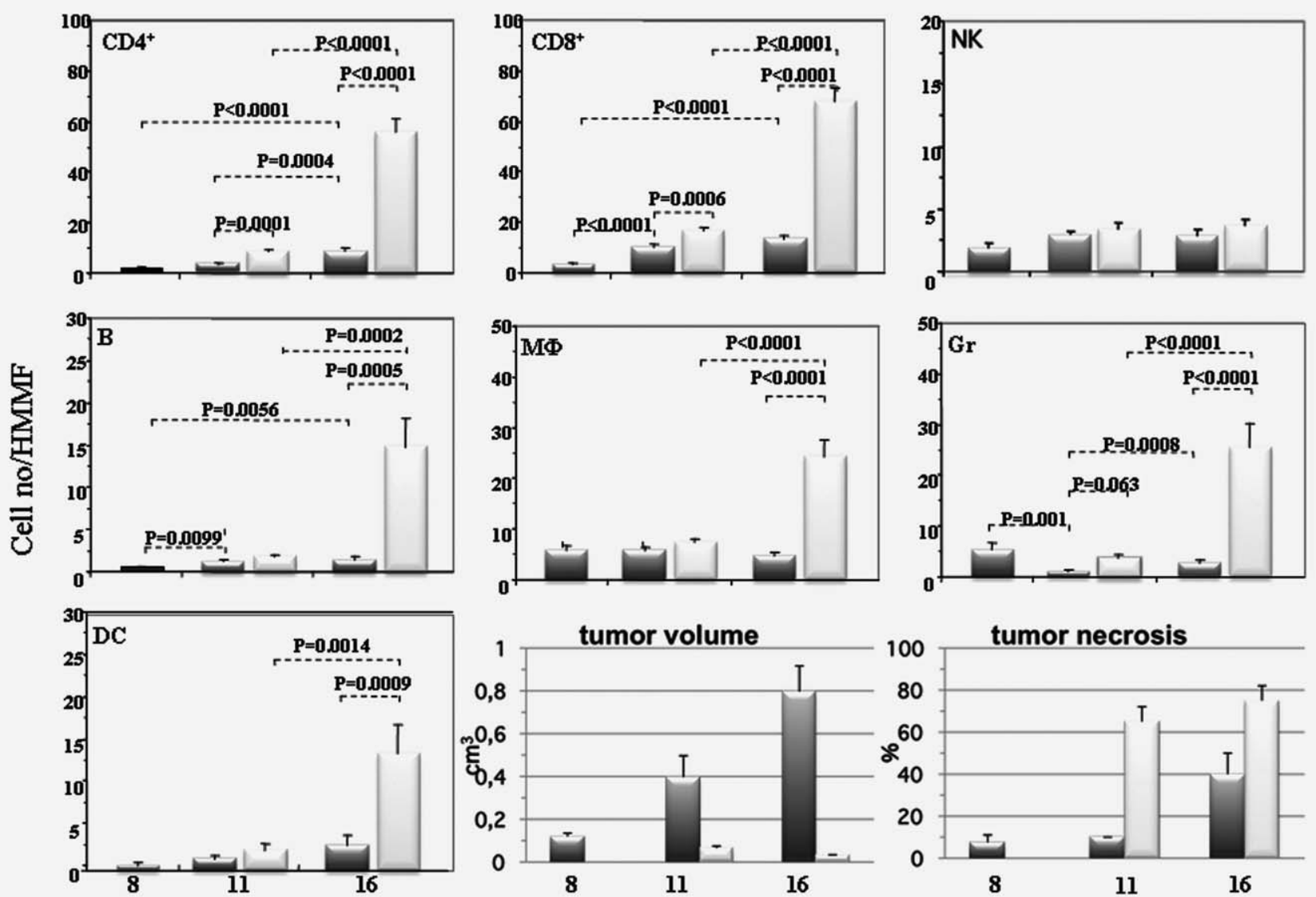

Figure 3. Evaluation of $\mathrm{N} 2 \mathrm{~A}$ infiltrates, volume variations, and necrosis at day 8, 11 and 16 after tumor cell implant in mice treated with L19-IL2/L19mTNFa (white columns) and in the untreated counterparts (gray columns). The following infiltrating cells were evaluated in immunohistochemistry using the antibodies reported in the M.M. section: $C D 4^{+}$T cells (CD4+); CD8 ${ }^{+}$T cells (CD8+); NK cells (NK); B cells (B); macrophages (MФ); granulocytes (Gr); dendritic cells (DC). Three mice per group were used. Results are expressed as the cell number (mean $\pm \mathrm{SE}$ ) per HMMF. P values of statistically significant differences between the groups connected by dotted lines are also reported. $\mathrm{N} 2 \mathrm{~A}$ tumor volume variations $\left(\mathrm{cm}^{3}\right)$ and necrosis (\%) were also evaluated (bottom-middle and -right panels) and expressed as mean \pm SD.

efficacy of the treatment, as $70 \%$ of NK-deprived animals were cured, as were the animals treated with control rat antibodies (Fig. $4 b$ ) or rabbit serum (data not shown). Removal of $\mathrm{CD}^{+} \mathrm{T}$ cells soon after tumor injection and before tumor therapy totally abrogated the therapeutic effects of the combination of L19-IL2 and L19mTNFa (Fig. 4b), thus demonstrating that $\mathrm{CD} 8^{+} \mathrm{T}$ cells are required for tumor eradication. Interestingly, when the mice were depleted of $\mathrm{CD}^{+} \mathrm{T}$ cells, the combined treatment with L19-IL2 and L19mTNF $\alpha$ still produced tumor eradication in $50 \%$ of animals (Fig. $4 b$ ). However, the treatment of $\mathrm{CD}^{+}{ }^{+}$-deprived mice with L19mTNF $\alpha$ alone (that cures per se about 30\% of immunocompetent mice, see Fig. $2 a$ ), resulted in the complete abrogation of therapeutic efficacy ( $0 \%$ of tumor rejecting mice, see Fig. $4 b$ ), strongly suggesting that the presence of $\mathrm{CD} 4^{+} \mathrm{T}$ cells was also important in mediating the immune rejection of tumor, but only in the absence of IL-2. A tumor challenge at day 50 was rejected by all tumor-cured mice, including the $\mathrm{CD} 4^{+}$-depleted animals. Taken together, these results indicate that the efficacy of antitumor treatment is strongly dependent on the presence of a functional adaptive immune system, particularly of $\mathrm{CD}^{+}$cells and, to a lesser extent, but only in the combined treatment, of $\mathrm{CD} 4^{+} \mathrm{T}$ lymphocytes.

\section{Involvement of $\mathrm{CD}^{+}$and $\mathrm{CD}^{+}{ }^{+}$cells in tumor rejection}

To assess whether immunity generated by the therapeutic approach could be transferred to naïve syngeneic recipients by specific cell subpopulations, we investigated total splenocytes, $\mathrm{CD} 4^{+}$and $\mathrm{CD}^{+} \mathrm{T}$ cells obtained from N2A tumorcured mice 12 days after tumor challenge. Unselected spleen cells fully protected naïve mice against a homologous tumor challenge (Fig. 4c), $\mathrm{CD}^{+}{ }^{+}$and $\mathrm{CD} 8^{+} \mathrm{T}$ cells protected $40 \%$ and $60 \%$ of naive mice, respectively, from tumor take, while co-injection of $\mathrm{CD}^{+}{ }^{+}$and $\mathrm{CD}^{+}$T cells protected $80 \%$ of mice, thus confirming that both $\mathrm{CD} 4^{+}$and $\mathrm{CD} 8^{+}$tumor specific primed $\mathrm{T}$ cells are the populations that are mainly involved in the process of tumor rejection after therapy. To further detail the functional correlates of antitumor immunity 


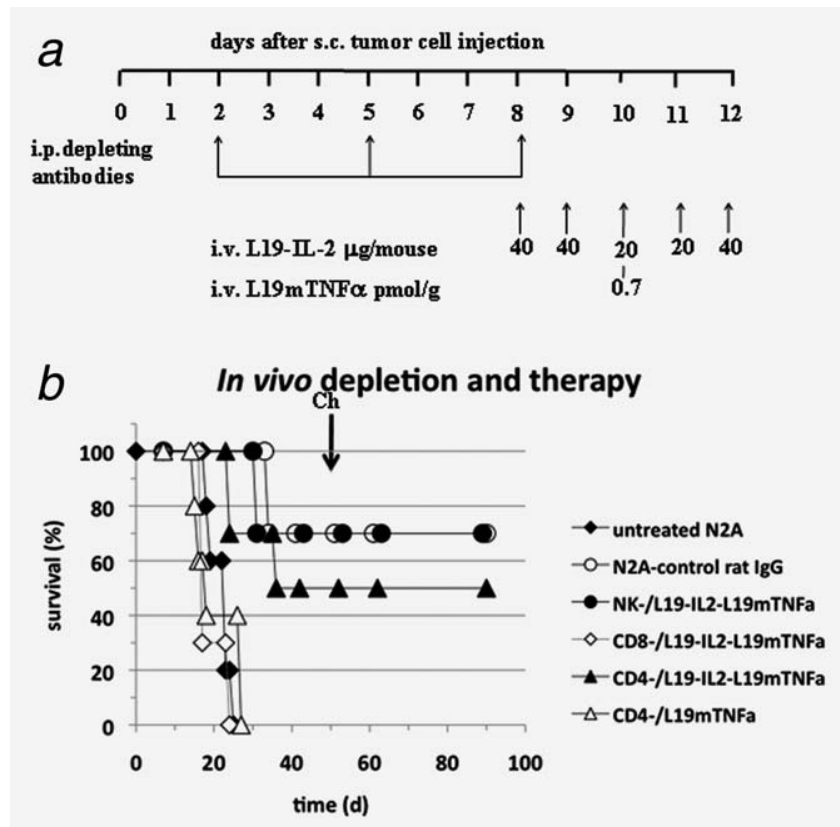

C Winn assay in vitro negative selection

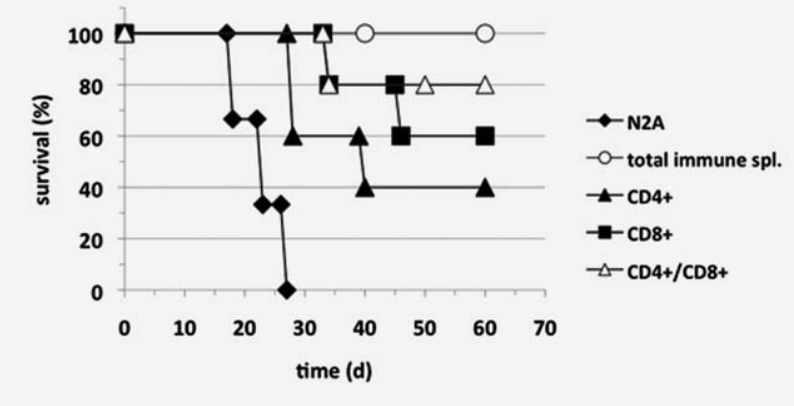

Figure 4. Study of the immune cell populations involved in NB eradication by therapy with L19-IL2/L19mTNF $\alpha$ (primary phase) and in the antitumor protection of naïve mice (memory phase). Following the protocol reported in (A), groups of 10 mice were in vivo depleted with antibodies or antisera directed to $\mathrm{CD}^{+}$or $\mathrm{CD} 8^{+} \mathrm{T}$ cells or to NK cells, as described in the M.M. section. N2A-bearing mice, either depleted or undepleted, were treated with the fusion proteins following the protocol reported in (a). In (b) the survival curves (\%) versus time (d) of the different groups of mice are reported. The arrows indicate a new tumor challenge with N2A cells. (c) Survival curves (\%) versus time (d) of groups of 10 naïve mice that received, at day 0 , a s.c. injection of N2A tumor cells and total immune spleen cells $(E: T=5: 1)$ or in vitro negatively selected $\mathrm{CD}^{+}$or $\mathrm{CD}^{+} \mathrm{T}$ cells or a mixture of $\mathrm{CD} 4^{+} / \mathrm{CD}^{+} \mathrm{T}$ cells.

triggered by the combined therapy with L19-IL2/L19mTNF $\alpha$, we evaluated the ability of total spleen cells from N2A tumor-cured mice to kill the NB cell lines in vitro in a classical $4-\mathrm{hr}{ }^{51} \mathrm{Cr}$ release assay. Three months after tumor cure, a low level CTL response, specific for N2A or for NIE-115 target cells, was found (Fig. 5a). At this time, a new challenge of cured mice with a tumorigenic dose of homologous N2A cells resulted in boosting CTL activity against homologous and heterologous tumor cells (Fig. 5b). The boosting of CTL activity was MHC class I restricted, as shown by the inhibition of lysis in the presence of anti-MHC class I but not anti-MHC class II mAbs (Fig. $5 c$ ). Importantly, this in vitro activity was associated with fast and complete tumor rejection in vivo after a tumor rechallenge (not shown). As CTL activity was MHC-I-restricted but apparently extended to 2 distinct tumors, we speculated that the $2 \mathrm{NB}$ cell lines might express common tumor-associated antigens. We thus investigated the CTL activity against survivin, a pan-tumor antigen involved in $\mathrm{T}$ cell responses in several malignancies, including human $\mathrm{NB} .^{32}$ When immune spleen cells were stimulated in vitro with the MHC class I-restricted GWEPDDNPI survivin peptide or SPSYVYHQF gp70env-derived AH1 peptide and tested in an IFN- $\gamma$-ELISPOT assay, there was a high frequency of IFN- $\gamma$ producing spleen cells only in response to the survivin peptide, thus indicating that response against survivin was at least part of the antitumor CTL activity generated in our experimental system (Fig. 5d).

We then evaluated whether the frequency of effector splenocytes producing IFN- $\gamma$ or IL-4, cytokines representative of type 1- and type 2- responses, respectively, was increased. A mixed Th1/Th2 response was still present 3 months after tumor cure (Figs. $6 a$ and $6 b$ ), thereby indicating that the tumor immunity was associated with the induction of both Th1 and Th2 types of response. Moreover, a new tumor challenge strongly increased the frequency of spleen cells displaying a Th1/Th2-type of response to tumor cells (anamnestic immune response), 2 weeks after homologous tumor challenge. Importantly, both IFN- $\gamma$ - and IL-4-secreting spleen cells responding to tumor challenge were mostly of the $\mathrm{CD} 4^{+}$ phenotype, as their function was blocked by pretreatment with anti-MHC class II but not anti-MHC class I antibodies (Figs. $6 a$ and $6 b$ ).

\section{Discussion}

All human as well as mouse NBs tested by us strongly express B-FN at the tumor vascular level (Fig. 1), and this expression is obviously prerequisite for the tumor drug delivery strategy based on the targeting ability of L19(scFv), a human recombinant antibody directed specifically against this proven marker of angiogenesis. ${ }^{19-21}$ Using the combination of L19-IL2 and L19mTNFa, a stable and long-lasting (up to six months) tumor eradication was achieved in $70 \%$ of N2A- and in 30\% of NIE115-bearing animals (Figs. $2 a$ and $2 b$ ). This result further emphasizes the importance of the synergistic therapeutic efficacy of combined L19-IL2 and L19mTNFa already observed by our group in other tumor models. ${ }^{24}$

One of the most relevant findings of the present investigation was the demonstration that the efficacy of the combined L19-IL2/L19mTNF $\alpha$ treatment against NBs was entirely dependent on the integrity of the cellular arm of the adaptive immune response. In fact, the functional elimination of $\mathrm{T}$ cells, particularly $\mathrm{CD}^{+}$cells, before administration of 


\section{a 3 mo after cure}

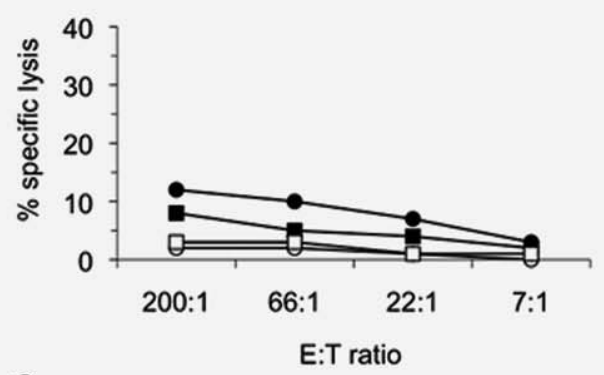

C
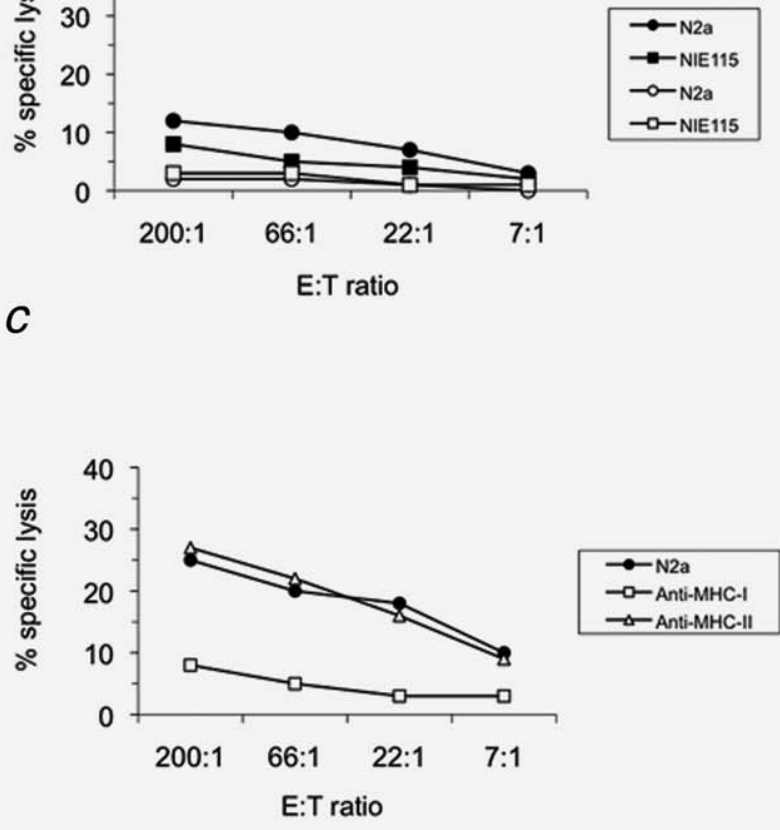

$b$

Figure 5. Specific lysis (\%) of N2A and NIE115 cells by different E:T ratios of splenocytes from naïve (open symbols) and N2A-cured mice (closed symbols) at 3 months after therapy with L19-IL2/L19mTNF $\alpha(a)$ and (b) after a s.c. tumor challenge. The specific lysis (black circles) was totally inhibited by anti-MHC class I antibodies (open squares) and unaffected by anti-MHC class II antibodies (open triangles) (c). Results are representative of 3 independent ${ }^{51}$ Chromium release experiments with similar results. (d) ELISPOT analysis of the frequency of IFN- $\gamma$ producing spleen cells (mean $\pm \mathrm{SD}$ ), stimulated with two MHC class I-restricted peptides, revealed that survivin peptide, but not gp70-env AH1 peptide, activates the release of IFN- $\gamma$ by memory cells that, being inhibited by anti-MHC class I antibodies, are CD8 ${ }^{+}$ T cells.

L19-IL2/L19mTNF $\alpha$ completely abrogated treatment efficacy. Indeed, $\mathrm{CD} 8^{+}$-deprived mice treated with L19-IL2/ $\mathrm{L} 19 \mathrm{mTNF} \alpha$ presented the same frequency of tumor take as that seen in control mice. These observations are especially important, as $\mathrm{CD}^{+}$CTL are believed to be the major antitumor effectors in vivo. Moreover, they underline the biological significance of the present therapeutic approach not only as a tool to directly kill the tumor cells in vivo, as we have shown through immunohistochemical analysis (Fig. 3), but also to facilitate the triggering of immune effectors that by themselves are responsible for complete tumor clearance.

Another relevant finding of the present investigation is that the combined therapeutic approach generated a protective antitumor immune response that was long-lasting and could be transferred to naïve recipients by adoptive cell transfer of immune $\mathrm{T}$ cells. Thus, the combined approach serves a dual purpose: to initiate the killing of tumor cells and to promote the effective immunization of and the acquisition of antitumor memory by the tumor-bearing host that will hopefully bring about tumor cure. In other words, the combined treatment induces a therapy-mediated vaccination against the tumor.
These results are reminiscent of those obtained by our group in other tumor therapy models, chief of which is the recently described therapy-induced tumor vaccination of mouse sarcomas and colon carcinomas after treatment with L19mTNF $\alpha$ and Melphalan. ${ }^{30,31}$ In this case, too, the efficacy of therapy was strictly dependent on the integrity of the adaptive $\mathrm{T}$ cell immune response. However, with the L19mTNFa/ Melphalan approach, it was possible to demonstrate the crucial role played by $\mathrm{CD}^{+}$Th cells in triggering and maintaining the immune response responsible for both tumor cure and tumor rejection upon challenge in tumor-cured mice. In essence, $\mathrm{CD} 4^{+}$Th cells were shown to be absolutely necessary in order to trigger, to induce the maturation of and to maintain the activity of the major antitumor effectors, the CD8 ${ }^{+} \mathrm{CTL}^{31}$

At first glance, our study would seem to downplay the role of $\mathrm{CD} 4^{+} \mathrm{Th}$ cells, as the removal of virgin $\mathrm{CD} 4^{+} \mathrm{T}$ cells after NB inoculum, but before combined L19-IL2/ L19mTNF $\alpha$ treatment, did not abrogate therapeutic efficacy as did the elimination of $\mathrm{CD}^{+} \mathrm{T}$ cells (Fig. 4). However, a complete analysis of the results and a critical evaluation of the L19-IL2/L19mTNFa approach versus the L19mTNFa/ Melphalan approach underscores the pivotal function of 


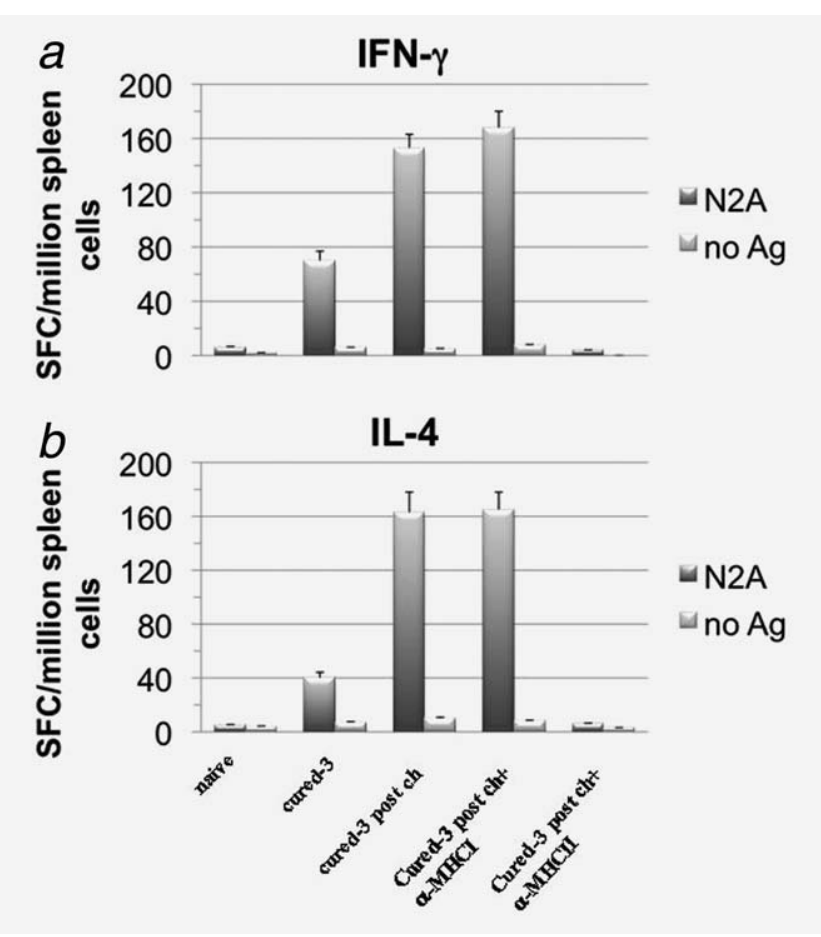

Figure 6. ELISPOT analysis of the frequency of IFN- $\gamma(a)$ and IL-4 (b) producing spleen cells from N2A-cured mice at 3 months after therapy with L19-IL2/L19mTNF $\alpha$ and after a s.c. tumor challenge (mean \pm SD). The mixed Th1/Th2 type of response was boosted by tumor challenge and totally inhibited by anti-MHC class II antibodies, confirming that tumor-specific $\mathrm{CD}^{+}$Th cells were the most responsive cells using this test.

$\mathrm{CD}^{+}{ }^{+}$Th cells also in this investigation. First of all, elimination of unprimed $\mathrm{CD}^{+} \mathrm{T}$ cells completely abrogated the therapeutic efficacy of $\mathrm{L} 19 \mathrm{mTNF} \alpha$ treatment, which was nevertheless capable of curing $30 \%$ of tumor-injected mice (Figs 2 and 4). Second, CD4 ${ }^{+} \mathrm{T}$ cells from tumor-cured mice were capable of transferring protection against tumor take to $40 \%$ of naïve mice compared to a protection rate of $60 \%$ transferred by $\mathrm{CD}^{+} \mathrm{T}$ cells, and together the 2 were able to protect up to $80 \%$ of naïve animals in adoptive transfer assays (Fig. 4c). This indicates that antitumor $\mathrm{CD}^{+} \mathrm{T}$ cell priming indeed occurred in vivo after combined therapy, and that the presence of the cells is crucial to maintaining antitumor memory. Thus, it would appear that $\mathrm{CD}^{+} \mathrm{T}$ cells were less important only when L19-IL2 was included in the combined therapy. Taken together, the above findings strongly suggest that the availability offered by the combined therapy of IL-2, the major cytokine required for proliferation of $\mathrm{CD}^{+}$and $\mathrm{CD} 8^{+}$ $\mathrm{T}$ cells and for the functional activation of $\mathrm{CD} 8^{+} \mathrm{CTL}$, may partially substitute the need during priming of having a large number of $\mathrm{CD}^{+}$Th cells to trigger and to induce the maturation of $\mathrm{CD}^{+}$CTL effectors. These and other hypotheses are presently under investigation in our laboratory.

Further phenotypic and functional characterization of the lymphocyte subpopulations present in mice undergoing com- bined L19-IL2/L19mTNF $\alpha$ therapy confirmed that CD4 ${ }^{+}$Th cells are present and deeply involved in the antitumor response generated against NBs. Indeed, spleen cells from tumor-cured mice displayed a mixed Th1/Th2 phenotype with increased frequency of both IFN- $\gamma$ and IL- 4 producing cells, most of which was inhibited by anti-MHC-II but not antiMHC-I antibodies. The finding that the antitumor response was associated to a mixed phenotype rather than to the generally believed unique protective Th1 phenotype is not surprising. Although in some tumor systems a polarized Th2 response promotes, and does not inhibit, tumor growth and spread $^{33}$ in other models a mixed Th1/Th2 immune response correlates with tumor rejection. ${ }^{34}$ Interestingly, we recently detected a protective Th1/Th2 type of immune response in mice receiving $\mathrm{L} 19 \mathrm{mTNF} / \mathrm{Melphalan}$ treatment. $^{31}$ Thus, a mixed, protective, antitumor Th1/Th2 response may be much more frequent than previously thought. Taken together, the above results should prompt careful reconsideration of the rather abused notion that, in vivo, a polarized Th1 response is synonymous with a protective antitumor immune response, whereas a polarized Th2 response may even favor tumor growth.

Most clinical experience on the immunotherapy of $\mathrm{NB}$ has focused primarily on monoclonal antibodies to the ganglioside GD2 (i.e., ch14.18 monoclonal) that selectively bind NB cells and facilitate antibody dependent cell-mediated cytotoxicity (ADCC) by FcR+ effector cells. ${ }^{35}$ The "immunocytokines" composed by anti-GD2 antibodies and IL-2 activate a strong innate immune antitumor response involving $\mathrm{NK}$ cells. $^{36-38}$ Potential NB-associated antigens capable of evoking CTL responses do exist, and several studies have shown that cytotoxic $\mathrm{T}$ cells (key immune cells for destroying tumor) recognize, albeit without clinical relevance, antigens expressed on the NB cell surface. ${ }^{39-41}$ Our results indicate that targeting $\mathrm{TNF} \alpha$ and IL-2 to NB vessels by $\mathrm{L} 19(\mathrm{scFv})$ can cure and vaccinate (therapeutic vaccination) animals, which thereafter reject NB challenge thanks to a tumor-specific T cell-mediated immune response able to complete the eradication of any $\mathrm{NB}$ residues and to establish a specific and protective antitumor memory. The maximum tolerated dose in patients, already established for L19-IL2 $2^{26,27}$ and to be calculated at the end of phase I clinical trials for L19-TNF $\alpha$, will provide the basis for planning a clinical trial using the combination of the two fusion proteins.

In conclusion, we believe that the findings reported here pave the way for alternative therapeutic strategies of $\mathrm{NB}$ based on the targeted delivery of biological cytotoxic compounds that not only kill most of the tumor cells but also, more importantly, trigger an effective and long-lasting antitumor adaptive immune response.

\section{Acknowledgements}

The authors thank Mr. Thomas Wiley for manuscript revision. 


\section{References}

1. Pinkerton CR, Blanc Vincent MP, Bergeron C, Fervers B, Philip T. Induction chemotherapy in metastatic neuroblastoma-does dose influence response? A critical review of published data standards, options and recommendations (SOR) project of the. National Federation of French Cancer Centres (FNCLCC). Eur J Cancer 2000;36: 1808-15.

2. Philip $\mathrm{T}$, Ladenstein $\mathrm{R}$, Lasset $\mathrm{C}$, Hartmann O, Zucker JM, Pinkerton R, Pearson AD, Klingebiel T, Garaventa A, Kremens B, Bernard JL, Rosti G, et al. 1070 myeloablative megatherapy procedures followed by stem cell rescue for neuroblastoma: 17 years of European experience and conclusions. European group for blood and marrow transplant registry solid tumour working party. Eur J Cancer 1997;33:2130-35.

3. Bowman L, Grossmann M, Rill D, Brown M, Zhong WY, Alexander B, Leimig T, Coustan SE, Campana D, Jenkins J, Woods D, Kitchingman G, et al. IL-2 adenovectortransduced autologous tumor cells induce antitumor immune responses in patients with neuroblastoma. Blood 1998;92: 1941-49.

4. Parmiani G, Rodolfo M, Melani C. Immunological gene therapy with ex vivo gene-modified tumor cells: a critique and a reappraisal. Hum Gene Ther 2000;11: 1269-75.

5. Rosenberg SA. Progress in human tumour immunology and immunotherapy. Nature 2001;411:380-84.

6. Lejeune FJ, Liénard D, Matter M, Rüegg C. Efficiency of recombinant human TNF in human cancer therapy. Cancer Immun 2006;6:6.

7. ten Hagen TL, Seynhaeve AL, Eggermont AM. Tumor necrosis factor-mediated interactions between inflammatory response and tumor vascular bed. Immunol Rev 2008;222:299-315.

8. Fearon ER, Pardoll DM, Itaya T, Golumbek P, Levitsky HI, Simons JW, Karasuyama H, Vogelstein B, Frost P. Interleukin-2 production by tumor cells bypasses $\mathrm{T}$ helper function in the generation of an antitumor response. Cell 1990;60:397-403.

9. Gansbacher B, Zier K, Daniels B, Cronin K, Bannerji R, Gilboa E. Interleukin 2 gene transfer into tumor cells abrogates tumorigenicity and induces protective immunity. J Exp Med 1990;172:1217-24.

10. Jones EY, Stuart DI, Walker NPC. Structure of tumor necrosis factor. Nature 1989;338:225-8.

11. Watanabe N, Niitsu Y, Umeno H, Kuriyama H, Neda H, Yamauchi N,
Maeda M, Urushizaki I. Toxic effect of tumor necrosis factor on tumor vasculature in mice. Cancer Res 1988;48:2179-83.

12. Folli S, Pèlegrin A, Chalandon Y, Yao X, Buchegger F, Lienard D, Lejeune F, Mach JP. Tumor necrosis factor can enhance radio-antibody uptake in human colon carcinoma xenografts by increasing vascular permeability. Int J Cancer 1993;53: 829-36.

13. Kristensen CA, Nozue M, Boucher Y, Jain RK. Reduction of interstitial fluid pressure after TNF- $\alpha$ treatment of three human melanoma xenografts. Br J Cancer 1996;74: 533-36.

14. Talmadge JE, Tribble HR, Pennington RW, Phillips $\mathrm{H}$, Wiltrout $\mathrm{RH}$.

Immunomodulatory and

immunotherapeutic properties of recombinant $\gamma$-interferon and recombinant tumor necrosis factor in mice. Cancer Res 1987;47:2563-70.

15. Roake JA, Rao AS, Morris PJ, Larsen CP, Hankins DF, Austyn JM. Dendritic cell loss from nonlymphoid tissues after systemic administration of lipopolysaccharide, tumor necrosis factor, and interleukin 1. J Exp Med 1995;181:2237-47.

16. Zimmermann VS, Bondanza A, Monno A, Rovere-Querini P, Corti A, Manfredi AA. TNF- $\alpha$ coupled to membrane of apoptotic cells favors the cross-priming to melanoma antigens. J Immunol 2004;172:2643-50.

17. Winkelhake JL, Gauny SS. Human recombinant interleukin-2 as an experimental therapeutic. Pharmacol Rev 1990;42:1-28.

18. Lejeune FJ, Ruegg C, Lienard D. Clinical applications of TNF- $\alpha$ in cancer. Curr Opin Immunol 1998;10:573-80.

19. Castellani P, Viale G, Dorcaratto A, Nicolo G, Kaczmarek J, Querze G, Zardi L. The fibronectin isoform containing the ED-B oncofetal domain: a marker of angiogenesis. Int J Cancer 1994;59: 612-18.

20. Castellani P, Borsi L, Carnemolla B, Birò A, Dorcaratto A, Viale GL, Neri D, Zardi L. Differentiation between high and low grade astrocitoma using a human recombinant antibody to extra domain-B of fibronectin. Am J Pathol 2002;161: 1695-1700.

21. Tarli L, Balza E, Viti F, Borsi L, Castellani P, Berndorff D, Dinkelborg L, Neri D, Zardi L. A high affinity human antibody that targets tumoral blood vessels. Blood 1999;94:192-98.

22. Santimaria M, Moscatelli G, Viale GL, Giovannoni L, Neri G, Viti F, Leprini A, Borsi L, Castellani P, Zardi L, Neri D, Riva P. Immunoscintigraphic detection of the ED-B domain of fibronectin, a marker of angiogenesis, in patients with cancer. Clin Cancer Res 2003;9:571-79.

23. Carnemolla B, Borsi L, Balza E, Castellani P, Meazza R, Berndt A, Ferrini S, Kosmehl H, Neri D, Zardi L. Enhancement of the antitumor properties of interleukin-2 by its targeted delivery to the tumor blood vessel extracellular matrix. Blood 2002;99: 1659-65.

24. Borsi L, Balza E, Carnemolla B, Sassi F, Castellani P, Berndt A, Kosmehl H, Birò A, Siri A, Orecchia P, Grassi J, Neri D, et al. Selective targeted delivery of TNF $\alpha$ to tumor blood vessels. Blood 2003;102: 4384-92.

25. Halin C, Gafner V, Villani ME, Borsi L, Berndt A, Kosmehl H, Zardi L, Neri D. Synergistic therapeutic effects of a tumor targeting antibody fragment, fused to interleukin 12 and to tumor necrosis factor a. Cancer Res 2003;63:3202-10.

26. Curigliano G, Spitalieri G, De Pas T, Noberasco C, Giovannoni L, Menssen H, Zardi L, Milani A, Neri D, de Braud F. A dose finding pharmacokinetic study of the tumor-targeting human L19-IL2 monoclonal antibody-cytokine fusion protein in patients with advanced solid tumors. In: ASCO Annual Meeting Proceedings, 2007. 25:3057.

27. Johannsen M, Roemer A, Spitaleri G, Curigliano G, Giovannoni L, Menssen HD, Zardi L, Neri D, Miller K, de Braud FG. Phase I/II study of the tumor-targeting human L19-IL2 monoclonal antibodycytokine fusion protein in patients with advanced renal cell carcinoma. In: ASCO Annual Meeting Proceedings, 2008. 26: 16032.

28. Borsi L, Balza E, Bestagno M, Castellani P, Carnemolla B, Biro A, Leprini A, Sepulveda J, Burrone O, Neri D, Zardi L. Selective targeting of tumoral vasculature: comparison of different formats of an antibody (L19) to the ED-B domain of fibronectin. Int J Cancer 2002; 102:75-85.

29. Mortara L, Castellani P, Meazza R, Tosi G, De Lerma Barbaro A, Procopio FA, Comes A, Zardi L, Ferrini S, Accolla RS. CIITA-induced MHC class II expression in mammary adenocarcinoma leads to a Th1 polarization of the tumor microenvironment, tumor rejection, and specific antitumor memory. Clin Cancer Res 2006;12:3435-43.

30. Balza E, Mortara L, Sassi F, Monteghirfo S, Carnemolla B, Castellani P, Neri D, Accolla RS, Zardi L, Borsi L. Targeted delivery of tumor necrosis factor- $\alpha$ to tumor vessels induces a therapeutic $\mathrm{T}$ cellmediated immune response that protects the host against syngeneic tumors of 
different histologic origin. Clin Cancer Res 2006;12:2575-82.

31. Mortara L, Balza E, Sassi F, Castellani P, Carnemolla B, De Lerma Barbaro A, Fossati S, Tosi G, Accolla RS, Borsi L. Therapyinduced antitumor vaccination by targeting tumor necrosis factor alpha to tumor vessels in combination with melphalan. Eur J Immunol 2007;37:3381-92.

32. Croce M, Meazza R, Orengo AM, Fabbi M, Borghi M, Ribatti D, Nico B, Carlini B, Pistoia V, Corrias MV, Ferrini S. Immunotherapy of neuroblastoma by an Interleukin-21-secreting cell vaccine involves survivin as antigen. Cancer Immunol Immunother 2008;57:1625-34.

33. Sakaguchi S. Naturally arising CD4+ regulatory $\mathrm{T}$ cells for immunologic selftolerance and negative control of the immune response. Annu Rev Immunol 2004;22:531-62.

34. Hung K, Hayashi R, Lafond-Walker A, Lowenstein C, Pardoll D, Levitsky H. The central role of $\mathrm{CD} 4+\mathrm{T}$ cells in the antitumor immune response. J Exp Med 1998;188:2357-68.

35. Hank JA, Surfus JE, Gan JC, Jaeger P, Gillies SD, Reisfeld RA, Sondel PM. Activation of human effector cells by a tumor reactive recombinant antiganglioside GD (2) interleukin-2 fusion protein (ch14.18-IL2). Clin Cancer Res 1996;2:1951-59.

36. Imboden M, Murphy KR, Rakhmilevich AL, Neal ZC, Xiang R, Reisfeld RA, Gillies SD, Sondel PM. The level of MHC class I expression on murine adenocarcinoma can change the antitumor effector mechanism of immunocytokine therapy. Cancer Res 2001;61:1500-07.

37. Lode HN, Xiang R, Varki NM, Dolman CS, Gillies SD, Reisfeld RA. Targeted interleukin-2 therapy for spontaneous neuroblastoma metastases to bone marrow. J Natl Cancer Inst 1997;89: 1586-94.

38. Lode HN, Xiang R, Dreier T, Varki NM, Gillies SD, Reisfeld RA. Natural killer cell- mediated eradication of neuroblastoma metastases to bone marrow by targeted interleukin-2 therapy. Blood 1998;91: 1706-15.

39. Oberthuer A, Hero B, Spitz R, Berthold F, Fischer M. The tumor-associated antigen PRAME is universally expressed in highstage neuroblastoma and associated with poor outcome. Clin Cancer Res 2004;10: 4307-13.

40. Rodolfo M, Luksch R, Stockert E, Chen YT, Collini P, Ranzani T, Lombardo C, Dalerba P, Rivoltini L, Arienti F, Fossati-Bellani F, Old LJ, et al. Antigenspecific immunity in neuroblastoma patients: antibody and T-cell recognition of NY-ESO-1 tumor antigen. Cancer Res 2003; 63:6948-55.

41. Sarkar AK, Nuchtern JG. Lysis of MYCN-amplified neuroblastoma cells by MYCN peptide-specific cytotoxic $\mathrm{T}$ lymphocytes. Cancer Res 2000;60: 1908-13. 